\title{
Cineclubismo como atitude crítica e sua urgência
}

Weliton Alécio Tarelho ${ }^{29}$

Este texto surge da importância de se apontar alguns eixos de atuação de um cineclube e sua maneira de operar dentro de uma sociedade cada vez mais tecnológica. $\mathrm{Na}$ grande maioria das vezes, a sociedade se utiliza explicitamente da educação e de ambientes legais de formação escolar para doutrinar indivíduos, intentando encaixá-los como peças em uma engrenagem que sustenta o modo de produção capitalista brasileiro. Fruto deste tipo de pensamento é a reprodução de uma cultura de consumo e alienação. Esta doutrinação pode ser vista também, é claro, no que diz respeito ao consumo de filmes. Há exceções quando, por exemplo um "filme arte" ou "de autor", recém-saído de um festival, acaba por flertar com uma grande produtora de mercado como Hollywood. Entretanto, na maioria dos casos, são superproduções esvaziadas de conteúdos que oferecem pouco respaldo para o espectador refletir sobre a obra. São filmes de narrativas repetitivas em que se altera a ótica, mas não o olhar. Representamse como corpos, rostos em enquadramentos, que reproduzem sem mudança alguma a mesma fórmula de feitio de um produto encomendado por uma demanda de mercado, para um público que aprendeu a aceitar o que lhes é ofertado.

\section{Conceito}

Um cineclube é um modelo de associação que teve início no começo do século passado e seu nome traz na palavra "clube", não aquilo que se conceitua hoje como algo fechado, elitista e para poucos, mas justamente o contrário. Quando os cineclubes surgiram a palavra clube remetia ao aspecto associativo e tinha uma conotação democrática e participativa, como os clubes operários ou de imigrantes desta mesma época. No dicionário, a palavra "cineclube" é definida como "uma associação que reúne apreciadores de cinema para fins de estudo e debate, assim como para exibição de filmes selecionados". Entretanto, existe ainda quem o entenda como uma atividade de mero lazer e entretenimento, por não compreenderem o poder transformador destes espaços, ou por considerar estas atividades algo subversivo, descreditando os teores

\footnotetext{
${ }^{29}$ Cineclubista. Formando em Filosofia pela UFPR. Membro do GECINE/NESEF - Grupo de Estudos Sobre Cinema e Educação do Núcleo de Estudos Sobre Ensino de Filosofia da UFPR.
} 
ideológicos do cineclubismo. O desconhecimento ou a confusão sobre o conceito favorece uma visão que inebria e dificulta seu real papel e importância, assim sua existência se dilui justamente onde não se compreende seus objetivos, realizações e sua estrutura específica dentro de comunidades, onde muitas vezes se faz protagonista do processo de formação cultural de um povo.

O cinema se popularizou no início do século XX na França amparado no desenvolvimento tecnológico. O maquinário, assim como seu produto (gravações e exibições), trariam uma nova e própria literatura de ideias, representando um campo de conhecimento advindo da atividade que iria naturalmente, compor seus símbolos de representação linguística tanto na técnica (campo, plano, movimentos, por exemplo), quanto no modus operandis (sentenças imagéticas de percepção: quando a imagem tem uma nevoa branca e demonstra que tais cenas se tratam de uma memória ou sonho, por exemplo), resultantes da prática do cinema. Este trabalho passou a criar uma linguagem autêntica e inteiramente nova. Após sua criação em 1895, pelos irmãos Lumière também se desenvolveu a necessidade de pensar o cinema para além do mero entretenimento. Riccioto Canudo foi o responsável por fundar o primeiro cineclube conhecido, chamado Club des Amis du Septième Art - (CASA), e militava em território francês pelo reconhecimento do cinema como uma forma de arte. Canudo ficou historicamente conhecido ao escrever, em 1911, o "Manifesto da Sétima Arte", onde incluía o cinema (para além das seis formas de arte descritas por Hegel no século XIX) como a sétima grande arte devido ao seu forte valor estético, congregando diferentes manifestações da própria arte dentro de si, independentemente do valor comercial dos filmes.

O tipo de associação chamada Cineclube carrega três características como pilares básicos, sem os quais não há atuação cineclubista. Um deles é a caracterização de uma estrutura horizontal e democrática, cuja finalidade não é calcada em lucro monetário, mas também não impede a circulação de recursos e investimento em sua própria atividade. Outro pilar é o compromisso ético-cultural. Estes dois pilares mencionados integram o que seria a identidade da associação como cineclube. Qualquer outro modelo associativo deve ter seu lugar na relação com os filmes, mas não se trata, nesse ponto, de um "cineclube", uma vez que estes trabalham consoantes à ideais distantes de aspectos empresariais ou hierárquicas. Quanto ao último pilar, seu caráter de atuação, diz respeito àquilo que difere os cineclubes e os identifica em determinado campo de trabalho, pois alguns se voltam para fins políticos, outros religiosos, estéticos 
ou filosóficos. Passa-se, com o tempo, a interferir no cotidiano pois nas atuações nascem uma célula de difusão cinematográfica, dotada de um modo específico de ver filmes, onde sua formação de público se dá na importância de conhecer mais profundamente uma obra e seus parâmetros de criação. É, pois, do cineclube que saem principalmente o espectador crítico assim como o curta metragista e o crítico de cinema, contribuindo na mudança de consciência e tomada de decisões de muitos indivíduos. Consequentemente, há uma forte mobilização de comunidades ou grupos, gerando movimentos, criando fatos e, muitas vezes, cineastas.

\section{Método, Identidade e Poder midiático.}

Além de se debruçar sobre a formação de público no seu aspecto teórico, intelectual, prático ou artístico, o cineclubismo é, sobretudo, a prática de se assistir e debater filmes coletivamente. É um espaço público onde as pessoas podem tomar em suas mãos a exibição e a discussão fílmica, como forma não apenas de se desalienar de uma cadeia de produção industrial e juntamente libertar-se de cartéis econômicos formados por exibidores e distribuidores, mas também de compreender melhor seu próprio processo cultural. Sendo assim, estes espaços comportam reflexões e uma análise mais aprofundada, tanto da criação fílmica e seus processos de produção e distribuição, como da realidade de cada um a partir da obra de arte.

É importante salientar que o método pelo qual muitos cineclubes ao longo da história e ainda hoje, se relacionam com uma obra, tende a seguir as práticas cineclubistas francesas do século passado, que tiveram grande influência do pensador, cineclubista, critico e teórico do cinema, André Bazin, também mentor da Nouvelle Vague Francesa, que de muitas formas veio a influenciar o cinema brasileiro e mundial. Assim, as sessões são compostas por três momentos: a apresentação do filme feita pelo mediador, a exibição e o debate (troca de ideias). Neste espaço, discutir e escrever tanto sobre ideias quanto sobre a própria maneira de se expressar, traz consigo, implicitamente aspectos políticos, históricos, estéticos ou culturais, observados pela reflexão a partir de dados imediatos da vida cotidiana, algo intrínseco a todo processo social, tendo neste caso, o filme como ponto de partida das discussões.

Ao longo da história do cinema como produto industrial, podemos denotar o estreitamento da relação entre o filme e o marketing, não só aquele que prepara o 
próprio público para a aceitação do filme produzido, mas também, o marketing que auxilia no convencimento sobre a necessidade de consumo de mercadorias, ideias, status social, ideologias específicas (muitas vezes preconceituosas e segregantes) e que excluem a proposta de uma possível educação estética a partir dos filmes, privando o grande público de saborear a verdadeira "experiência do cinema". A abordagem do cinema sob o viés do entretenimento ou apenas como item de consumo, traduz uma imagem bastante caricata da indústria cultural e que, muitas vezes, aponta para problemas. Por vezes, torna-se nas mãos de alguns, uma ferramenta útil na construção de discursos altamente ideológicos (vide o cinema nazista, fascista ou de guerra norte americano), ou como um nicho altamente lucrativo, como verificamos no cinema produzido em Hollywood. Por outro lado, é preciso mencionar que o uso de filmes também pode se dar de maneira a auxiliar, por exemplo, na transmissão de conteúdos curriculares, possibilitando a colaboração direta na formação de um individuo critico e responsável.

Quando se trata do real poder do cinema, é preciso atentar para o fato de que o ato de mentar ${ }^{30}$ está envolto tanto em imagens quanto em palavras que vão, em sua sucessão e ao longo do tempo, dando forma ao que se refere a valores, crenças ou superstições, assim como a conteúdos emocionais. Tudo isso trazido pela experiência cotidiana e direta no mundo, que se fez é claro, a partir de uma cultura que implantou seus parâmetros de diversas formas, durante o crescimento e a assimilação do real por parte do indivíduo que trabalha a montar este seu pensar. Sendo assim, o cinema, neste campo, interage diretamente com estas formas do pensamento, dando rumo não apenas aos olhares durante a duração das cenas, mas aos cortes, ângulos de câmera e composições variadas, controlando a percepção da audiência e dominando as respostas cerebrais dos espectadores. De maneira geral, essa individualidade mental que dá a cada um características únicas devido sua própria experiência, está sempre sujeita à consternação de informações que tem o forte papel de homogeneizar o entendimento das coisas, e em ultima instância, somado à falta de ética e certo descompromisso com

\footnotetext{
${ }^{30}$ A ideia sob esta palavra aqui inserida é a de primeiramente abrir caminhos sem esgotar seu sentido, sendo assim, ao que nos serve, a palavra "mentar" está para o "pensar" de modo a representar, como no poema "A Maquina do Mundo" da obra "Claro Enigma" de Drummond, o ato de se entregar às malhas da razão por meio do entendimento do mundo, sem no entanto, partindo de rememoração e labor mental, se render ao eu cultural formado, definido, como na batalha travada contra tamanha máquina em uma estrada pedregosa de minas pelo autor do poema. Mentar está para o ato do pensamento crítico na lida seja com os hermetismos da linguagem alegórica, seja com os fatos mais imediatos do cotidiano, todos frutos da experiência pessoal onde imagem e palavra se articulam no engenho humano, e decorrem desde um mero conceito à mais vasta epifania. (N.do.A)
} 
ideários comuns por parte dos detentores das grandes mídias (redes de tevês e rádios), manipulando as informações, decide a maneira e o conteúdo segundo critérios próprios e ligados à interesses corporativistas cujo intuito é sempre a segregação e o mantenimento de seu próprio poder. Desta forma, há um subjulgamento das massas quando o que deveria imperar é a imparcialidade e o compromisso com a reflexão e o debate entre os sujeitos. Não sendo fruto de reflexão própria, estes conteúdos pensados e produzidos por veículos midiáticos, podendo-se incluir filmes ou programas de auditório e de rádio, buscam nada mais que estabelecer um colonialismo ideológico que causa a falência da autonomia do povo, impossibilitando-o de pensar até mesmo sobre sua real condição frente ao mundo, um grande condicionamento político. O elevado grau de impotência frente a esta realidade e a esterilidade, no que diz respeito a tomadas de decisões frente a mudanças necessárias, costumam ser os efeitos dessa briga injusta, uma vez que são meios de convencimento muito eficazes.

O objetivo desse estudo é tentar, em poucas palavras, demonstrar a importância e a urgência dos "cuidados com o cinema", e ao mesmo tempo propor que qualquer indivíduo possa acessar as obras cinematográficas com um olhar coletivo (de troca) e diligente, desde que se intente a compreensão e a utilização do cinema como agente de conhecimento. Indo além, podemos dizer que a sessão de cinema soa como um modo de se desenvolver, de se formar um tanto mais atento a realidade, podendo desvendar as mazelas cotidianas e estruturais que acabam por velar erros e má atuação na vida em sociedade. Assim, o cineclubismo pode ser visto como um ato revolucionário, um espaço de discussão e de construção de visões críticas, de aprofundamento teórico e prático, onde o filme é o grande mediador para a construção de uma livre e sólida formação estética e cultural. Pensamos um cinema que ajude o indivíduo a adquirir certa autonomia para compreender o mundo que o cerca, que o auxilie na construção de sua identidade, que supere os individualismos a partir do respeito às diferenças e da superação do preconceito. Trata-se de um projeto de formação crítica para além dos limites da família e do Estado, para além dos limites institucionais responsáveis pela educação formal, uma vez que o cineclube transcende as paredes da sala de aula ao internalizar e sistematizar reflexões, possibilitando a significação e ressignificação do pensamento por meio de filmes.

A partir do contato com películas, e sob uma determinada postura, existe a possibilidade da internalização de um ato que da dinâmica à significação e 
ressignificação do pensamento, logo, da narrativa pessoal e da própria ação no mundo. Há nos cineclubes a tendência ao trabalho focado na formação de um sujeito integral, capaz de identificar questões e problemáticas relativas ao seu meio e estabelecer métodos para saná-las, o que, na conjuntura atual, é um recurso de considerável importância, atribuindo ao cineclubismo uma tarefa emancipadora.

Denotadas as características de um cineclube, conceito, definição e, principalmente a amplitude das formas de atuação, este tipo de associação se debruça sobre todo processo de produção cinematográfico de maneira a analisar não apenas a obra em si e suas formas ou nuances estéticas, mas também seu conteúdo como ferramenta do pensar a realidade lançando mão de um caráter formativo de leitura e interpretação. A ideia é que haja disposição ao esforço de incorrer no árduo trabalho do pensar, do interpretar uma obra para além de suas caras, de modo a decifrar certas alegorias. Ismail Xavier, em uma entrevista à revista Educação \& Realidade da Universidade federal do Rio Grande do Sul, orienta:

\begin{abstract}
Nesse terreno, seria ilusório supor que a relação produtiva e enriquecedora com as imagens e narrativas desconcertantes, se apoie na força exclusiva de um saber das formas e de um repertório analítico que nos capacite a uma recepção "adequada", pois aqui, como em outros terrenos, quase tudo depende da postura, de uma disponibilidade, de uma forma de interagir com as imagens (e narrativas), que têm a ver com todas as dimensões da nossa formação pessoal e inserção social. A recepção deve ser um acontecimento (original) não redutível a esta ideia de que o "especialista" (sabedor de códigos) detém a chave para ler os filmes da forma mais competente.(XAVIER, 2008, p. 16)
\end{abstract}

A partir disso, trataremos do cineclubismo como o meio pelo qual o individuo não adquire verdades, mas uma determinada postura frente às obras, podendo entender também os processos pelos quais a imagem é utilizada como instrumento de manipulação, homogeneização e domínio em massa. O cineclube é um espaço formativo, um tipo de associação pela qual seus membros adquirem certa sensibilidade, intentando uma visão de mundo (Weltanschauung) não mais unilateral, mas que passa a compartilhar com a realidade uma maior gama de olhares e posicionamentos e por fim, uma literatura de ideias que possibilite o processo de dês-alienação.

No mais, tendo como base a Lei 13.006 de 26 de junho de 2014 que instituiu a obrigatoriedade de exibição de pelo menos duas horas mensal de filmes brasileiros na escola, apontamos para a urgência de pensar o cineclube como uma proposta de aplicação prática da lei escolar, contribuindo para a formação estética e cultural dos jovens. A proposta, além de trazer o reconhecimento da arte nacional do cinema, traz a 
possibilidade de construção de uma nova cultura fílmica, superando os antagonismos produzidos pelo cinema comercial, viabilizando uma proposta de caráter crítico e conscientizador, voltada ao pleno exercício da cidadania. Antes de vermos o filme apenas como um divertimento direcionado à satisfação pessoal e ao gosto individual, poderíamos fazer o exercício de pensá-lo dentro de um projeto de desenvolvimento intelectual e cultural. Sendo assim, como já foi dito, é urgente a preocupação com o cinema a partir do cineclube, tratando de observá-lo em suas diferentes abordagens e manifestações. É irrefutável a ideia de que o cineclubismo funciona como agente direto na formação social, política, estética e cultural, e diante da realidade atual não podemos fechar os olhos diante dos abismos educacionais, dentro dos quais o trato cuidadoso com a obra cinematográfica pode ser uma contribuição valiosa no itinerário formativo dos jovens.

\section{Referências}

CARRIERE, J. C. A linguagem secreta do cinema. Nova Fronteira, 2006.

ARISTARCO, G. História das teorias do cinema. Lisboa: Arcádia, 1961.

GOMES, P. E. S. Cinema: trajetória no subdesenvolvimento. São Paulo: Paz e Terra, 1996.

LISBOA, F.S.G. O cineclubismo na América Latina: idéias sobre o projeto civilizador do movimento francês no Brasil e na Argentina (1940-1970). In: CAPELATO, Maria Helena; MORETIN, Eduardo; NAPOLITANO, Marcos e SALIBA, Elias Thomé. História e cinema: dimensões históricas do audiovisual. São Paulo: Alameda Casa Editorial, 2007.

O QUE É UM CINECLUBE. Direção e Produção: Pão com Ovo Filmes. Rio Grande do Sul (BR)

Pão com Ovo Filmes, 2007. Disponível em: https://www.youtube.com/watch?v=2mhYM-zm7tI

Acesso em: 30/06/2018.

XAVIER, I. Um Cinema que Educa é um Cinema que nos faz Pensar. Educação \& Realidade, UFRGS, 2008, ed.33 v.1. 